\title{
Mechanical properties of recycled glass fibre reinforced nanoclay/unsaturated polyester composites
}

\author{
Umar Abdul Hanan ${ }^{1}$, Shukur Abu Hassan 1, 2, *, Mat Uzir Wahit ${ }^{2,3}$, Rohana Yusof ${ }^{4}$, Balqis Omar ${ }^{5}$, Siti Khalijah \\ Jamal 1 \\ ${ }^{1}$ Faculty of Mechanical Engineering, Universiti Teknologi Malaysia, Skudai, Johor, Malaysia \\ ${ }^{2}$ Centre for Composites, Universiti Teknologi Malaysia, Johor Bahru, Johor, Malaysia \\ ${ }^{3}$ Faculty of Chemical and Energy Engineering, Universiti Teknologi Malaysia, Skudai, Johor, Malaysia \\ ${ }^{4}$ Institute of Industrial Technology, Universiti Kuala Lumpur Malaysian, 81750 Bandar Seri Alam, Johor, Malaysia \\ ${ }_{5}^{5}$ Faculty of Civil Engineering, Universiti Teknologi Malaysia, 81310 Skudai, Johor, Malaysia
}

\section{A R T I C LE IN F O}

\section{Article history:}

Received 4 November 2016

Received in revised form

5 January 2017

Accepted 5 January 2017

\section{Keywords:}

Mechanical recycling

MMT nanoclay

GFRP recyclates

Tensile properties

Scanning electron microscopy

\begin{abstract}
A B S T R A C T
The purpose of this study is to study the effects of montmorillonite (MMT) nanofiller on the mechanical properties of glass fibre recyclates (rGF) reinforced unsaturated polyester (UP) composites. Alumina-silicates nanoclay such as MMT can improves the mechanical performance of polymeric composites. This study uses the mechanical recycling process to grind the GFRP waste into recyclates. MMT nanoclay was dispersed into UP using ultrasonicator. Different weight percentage of rGF at $25 \mathrm{wt} . \%, 30 \mathrm{wt} . \%$ and $40 \mathrm{wt} \%$ were mixed in UP-MMT resin and formed into composites plate using compression moulding. Preliminary study shows that, the tensile strength of $25 \mathrm{wt}$ \% raw rGF-UP composites was approximately $50 \%$ lower than of UP. Therefore, raw rGF was sieved into coarse and fine grade to improve the tensile properties of the composites. Compared to raw rGF, sieved rGF has better tensile strength due to better fibre distribution of rGF and uniformed fibre length. Coarse rGF composites which contain relatively larger aspect ratio (longer fibre length) have better tensile properties than fine rGF. The inclusion of MMT nanofiller in polyester resin enables the tensile strength of the composites to increase. For example, the tensile strength of $40 \mathrm{wt} \%$ fine rGF-3 wt.\% MMT hybrid composites is higher by $14 \%$ than the non-hybrid 40 wt.\% fine rGF. Scanning electron microscopy shows good fibre/resin adhesion for MMT below $3 \mathrm{wt} \%$. While at $5 \mathrm{wt} . \%$ MMT, the UP resin becomes degraded and developed poor adhesion of resin to the recyclate fibres.
\end{abstract}

(C) 2017 The Authors. Published by IASE. This is an open access article under the CC BY-NC-ND license (http://creativecommons.org/licenses/by-nc-nd/4.0/).

\section{Introduction}

Due to the versatility of GFRP material, the demands for GFRP products are steadily growing (Goodship, 2009). Despite the growing number of composites material applications, fibre reinforced plastics products mainly made from thermoset resin are difficult to recycle because the material is fully cured and this process is irreversible (Yang et al., 2012). Issues such as uncontrolled disposal of fibre reinforced polymer composites are concerning many researchers. Therefore, using recycled GFRP in

\footnotetext{
* Corresponding Author.

Email Address: shukur@utm.my (S. A. Hassan)

https://doi.org/10.21833/ijaas.2017.03.001

2313-626X/@ 2017 The Authors. Published by IASE.

This is an open access article under the CC BY-NC-ND license

(http://creativecommons.org/licenses/by-nc-nd/4.0/)
}

composites products is a great solution to reduce GFRP waste in landfills (Otheguy et al., 2009).

Single fibre tensile testing method was used to compare the strengths of virgin and recycled glass fibres (Palmer, 2009). Mechanical recycling of waste of injection moulded GFRP products was used, which involved grinding and separation of the recycled products. For gage length $5 \mathrm{~mm}$, the tensile strength of recovered glass fibre dropped 18\% and Young modulus dropped $3.8 \%$. For gage length $10 \mathrm{~mm}$ and $15 \mathrm{~mm}$, the difference between virgin and recycled fibre also show similar trend as $5 \mathrm{~mm}$ gage length. Similar study by Kao et al. (2012) showed that the recovered glass fibres by hydrolysis process only maintain half of its original tensile strength of virgin glass fibre.

A study had been done on reusing short fibres obtained from the recycled thermoset composite to develop new composite materials. Initially, the glass 
fibre recyclates were processed from composites waste using mechanical grinding method. The recovered fibres were incorporated into the virgin matrix. The material composition of the composites were as follows: recycled glass fibres incorporated with polypropylene at $40 \mathrm{wt} \%$ (volume fraction: $12 \%)$ concentration. The tensile strength of the new thermoplastic composites reinforced by recycled fibres is slightly greater (25 $\mathrm{MPa}$ ) than the virgin fibre composites (24 MPa). The modulus of elasticity of the new generation of composites reinforced by recycled fibre is slightly lower than virgin fibre composites by $5 \%$ (Asmatulu et al., 2014).

Bernasconi et al. (2007) investigated the effects of mechanical recycling on the tensile strength of an injection moulded polyamide reinforced glass fibres composite. The virgin glass fibre used in this study is E-glass short fibre of $10.5 \mu \mathrm{m}$ average diameter. Composite with virgin glass fibre has tensile strength of 187.4 $\mathrm{MPa}$, while composite with recycled glass fibre has $165.5 \mathrm{MPa}$. Besides that, composite with virgin glass fibre has elastic modulus of $10.84 \mathrm{GPa}$ while composite with recycled glass fibre has 10.27 GPa.

The lack of mechanical strength in recycled glass fibre composites might possibly be overcome by the inclusion of nano-clay materials. Clay mineral as nanofiller in polymer matrix composites, discovered by Toyota research group, were found to be promising in improving mechanical properties at low loadings of the reinforcing filler (Kaynak et al., 2009). Polymers incorporating dispersed nanofiller clay minerals promote enhanced mechanical properties (Ozkoc et al., 2008).

The dispersion of silicates in nanoclay-polymer matrix composites (NPC) can be observed through transmission electron microscopy. The structure of nano-clay silicates platelet can be in the form of intercalated (polymer chain in between the clay platelets) or exfoliated (the silicate platelets dispersed randomly in polymer) as shown in Fig. 1. Usually, exfoliated nano-composites are preferred because it exhibits better performance in term of mechanical, thermal, and flame-retardant properties. However, exfoliation and fully dispersion of nanoclay in NPC still remains a difficulty to achieve (Karippal et al., 2011).

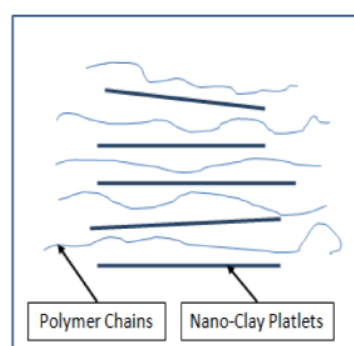

Intercalated

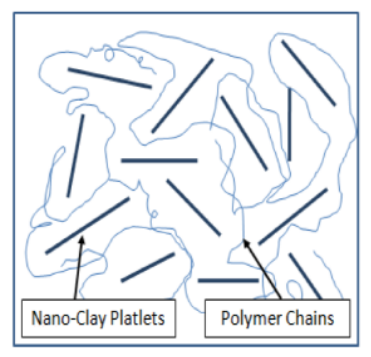

Exfoliated and ispersed
Fig. 1: Schematic illustration of nano-clay dispersion in polymer matrix composites

Shrinkage of the cured resin gives rise to residual stresses in polymer matrix composites, which causes dimensional problems during composite fabrication and contribute to premature failure of the product. However, the issue of resin shrinkage can be solved by the addition of nanofiller such as montmorillonite (Parvinzadeh et al., 2010). The study shows that addition of $5 \%$ by weight of montmorillonite (MMT) has reduce the volumetric shrinkage of unsaturated polyester (UP) from $9.8 \%$ down to $2.5 \%$ only. Other than that, the bending stiffness of UP has also increase by $7 \%$.

Study by Shokrieh et al. (2012) showed that the inclusion of MMT in glass fibre reinforced epoxy composites has improved the mechanical performance of the composites. The improvement is due to extremely high surface to volume ratios and the nanometer size dispersion of MMT in polymers. Microstructure analysis shows that the MMT in composites also provide good interfacial bonding between glass fibres with epoxy. The optimum weight percentage of MMT is found to be $6 \%$ for enhanced tensile and flexural properties of the composites.

Based on the literature, it is found that MMT nanofiller have the potential to enhance the performance of glass fibre recyclate polyester composites. Hence, this research paper will discuss the effects of montmorillonite (MMT) nanofiller on the mechanical properties of glass fibre recyclates (rGF) reinforced unsaturated polyester (UP) composites.

\section{Materials and methods}

GFRP waste was collected from local composites manufacturers and pulverised by using a hammer mill and crusher machine as shown in Fig. 2. The glass fibre recyclate ( $\mathrm{rGF}$ ) was filtered by using a sieve shaker into two categorical sizes which is fine and coarse rGF. In this study, three types of fibre were used which is coarse, fine and raw (not sieved).

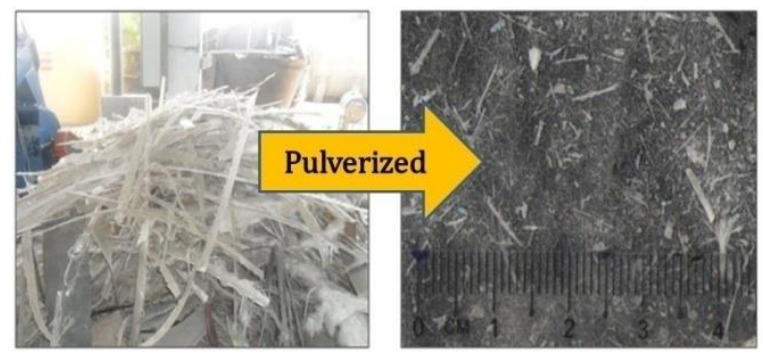

Fig. 2: Waste from trimmings of GFRP water tanks and septic tanks (left) were pulverised into glass fibre recyclates (right)

Orthophthalic general purpose unsaturated polyester (UP) from S\&N Chemicals Sdn. Bhd., Johor, Malaysia was used as the matrix. Methyl ethyl ketone peroxide (1 part per hundred parts of resin) was used as catalyst. Different rGF fibre loading ranging from $25 \mathrm{wt} \%$ to $40 \mathrm{wt}$.\% was used as reinforcement. The preparation for hybrid nanocomposites uses montmorillonite nanofiller (MMT) Nanomer I.42E from Nanocor $₫$, USA. The nanofillers were oven- 
dried for 6 hours at $80^{\circ} \mathrm{C}$ to removes any possible moisture. MMT nanofillers were then mixed with UP using a mechanical stirrer and then by an ultrasonic homogenizer for 2 hours. The sonicated mixture of UP-MMT contains high amount of bubbles and were degassed using a vacuum chamber. Prior to compression moulding process, recyclates were evenly distributed into the mould cavity. Bristle roller was used to thoroughly wet the recyclates with the resin and to removes air pockets during the hand lay-up process (Fig. 3). Subsequently, the mould was pressed by using a hydraulic compression moulding machine at 100 bars. The prepared samples were tested for tensile properties in accordance of ASTM D3039 Standard Test Method for Tensile Properties of Polymer Matrix Composite Materials. Scanning electron microscope (SEM) was used to observe the morphology of the test samples.

\section{Results and discussion}

Table 1 shows the composition of rGF after been sieved. Powder rGFs were collected from the lowest pan of the sieve shaker. The average fibre length of powder rGF is smaller than $1 \mathrm{~mm}$. The relatively low aspect ratio of powder means it does not have the potential to be reused as reinforcement in composites. Meanwhile, fine and coarse rGF are fibrous and indicate good length-to-diameter ratio compared to powder. Therefore, fine and coarse grades were selected as reinforcement in this study. However, coarse rGF might not provide better reinforcement compared to fine rGF because coarse rGF contains composites particles or fragments (approx. 10 wt.\%) which were not properly mill during the crushing of GFRP waste. Table 2 shows the comparison between tensile properties of sieved (fine and coarse) rGFs and raw rGFs; and between hybrid and non-hybrid samples. The samples is coded as nrGF, where $n$ is the weight percentage of rGF used in the sample formulation.

The data shows that sieved rGF composites showed better tensile strength than raw rGF composites because of more uniform fibre geometry and homogeneous fibre distribution (Palmer, 2009). Coarse 30rGF composite has higher tensile strength and tensile modulus than Fine 30rGF composites by $57 \%$ and $20 \%$ respectively. The reason is Coarse $\mathrm{rGF}$ has larger aspect ratio (longer fibre as shown in Table 1) than Fine rGF which increases the mechanical performance of the composites. However, tensile strength of coarse rGF drops at $40 \mathrm{CrGF}$ as the amount recyclates becomes saturated in the composites and cannot bind effectively with UP resin.

Table 1: Composition and fibre length of rGF grade after sieving process of raw rGF

\begin{tabular}{ccc}
\hline Recyclate Grade & Weight Composition (\%) & Fibre Length (mm) \\
\hline Powder & 40 & $<1$ \\
Fine & 32 & $1-6$ \\
Coarse & 28 & $4-15$ \\
\hline
\end{tabular}

Table 2: Tensile properties of rGF composites and hybrid rGF/MMT composites

\begin{tabular}{cccc}
\hline Sample Name & rGF Grade & Tensile Strength (MPa) & Tensile Modulus (GPa) \\
\hline UP & - & $29.80 \pm 1.89$ & $2.68 \pm 0.09$ \\
3MMT & - & $33.79 \pm 1.54$ & $2.84 \pm 0.05$ \\
Raw 25rGF & Not sieved & $17.74 \pm 2.66$ & $4.03 \pm 0.29$ \\
25 FrGF & Fine & $20.90 \pm 2.35$ & $3.99 \pm 0.30$ \\
30 FrGF & Fine & $22.80 \pm 2.29$ & $4.44 \pm 0.33$ \\
40 FrGF & Fine & $24.22 \pm 2.10$ & $5.00 \pm 0.42$ \\
40FrGF-3MMT & Fine & $28.39 \pm 2.23$ & $5.21 \pm 0.51$ \\
40FrGF-5MMT & Fine & $18.54 \pm 1.99$ & $5.18 \pm 0.69$ \\
25 CrGF & Coarse & $22.52 \pm 1.35$ & $4.21 \pm 0.27$ \\
25CrGF-1MMT & Coarse & $25.50 \pm 2.04$ & $4.00 \pm 0.28$ \\
25 CrGF-2MMT & Coarse & $29.10 \pm 1.97$ & $4.18 \pm 0.13$ \\
25 CrGF-3MMT & Coarse & $28.50 \pm 2.05$ & $3.57 \pm 0.70$ \\
30 CrGF & Coarse & $35.77 \pm 4.19$ & $5.13 \pm 0.16$ \\
30 CrGF-1MMT & Coarse & $27.64 \pm 2.81$ & $5.86 \pm 0.41$ \\
30 CrGF-2MMT & Coarse & $28.84 \pm 2.80$ & $5.62 \pm 0.36$ \\
30 CrGF-3MMT & Coarse & $30.83 \pm 2.25$ & $5.58 \pm 0.48$ \\
40 CrGF & Coarse & $23.90 \pm 3.1$ & $6.08 \pm 0.51$ \\
\hline Note: 3MMT meant 3 wt.\% of montmorillonite added into polyester resin. FrGF meant Fine rGF. CrGF meant coarse rGF.
\end{tabular}

Hybrid nano-composites material shows improvement when compare to composites without any nanofiller addition. Previous research shows that MMT can reduce resin shrinkage in composites, hence reduces residual stress between fibre and resin (Parvinzadeh et al., 2010). The tensile strength of 40 FrGF-3MMT hybrid composites is higher by $14 \%$ than the non-hybrid 40 FrGF.

However, 5 wt.\% of MMT does not provide any reinforcement as proven by the result of $40 \mathrm{FrGF}$ 5MMT (Fig. 4). This finding shows similarities with research by Kornmann et al. (1998), where the tensile strength of UP drops when MMT nanoclay weight content reaches $5 \%$.

Other than that, Coarse $25 \mathrm{rGF}$ has better tensile strength with the inclusion of MMT clay at $2 \mathrm{wt} . \%$ and 3 wt.\% as shown in Fig. 5. Previous study shows that MMT nano-clay at 2 wt.\% provide the highest increased in tensile strength of UP/glass fibre/clay composites (Kusmono and Mohd, 2013). However, $30 \mathrm{CrGF}$ does not developed improvement in term of tensile strength when MMT were introduced into the 
composites. In fact, the tensile strength of 30CrGFMMT is slightly lower than $30 \mathrm{CrGF}$. The high amount of fibre loading and compactness of recyclates in $30 \mathrm{CrGF}$ could possibly hinder the relatively viscous UP/MMT resin to thoroughly wet all the recyclate fibre inside the mould during fabrication process. According to Morote-Martinez et al. (2011), a linear increase of viscosity of unsaturated polyester resin was obtained by adding MMT nanoclay.

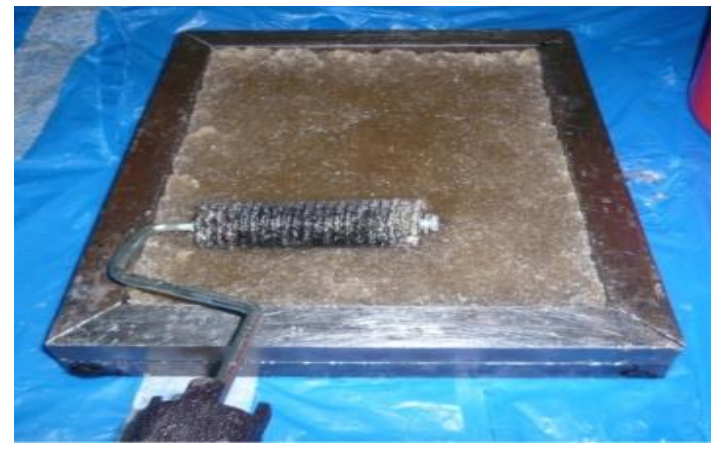

Fig. 3: Hand lay-up of rGF composites

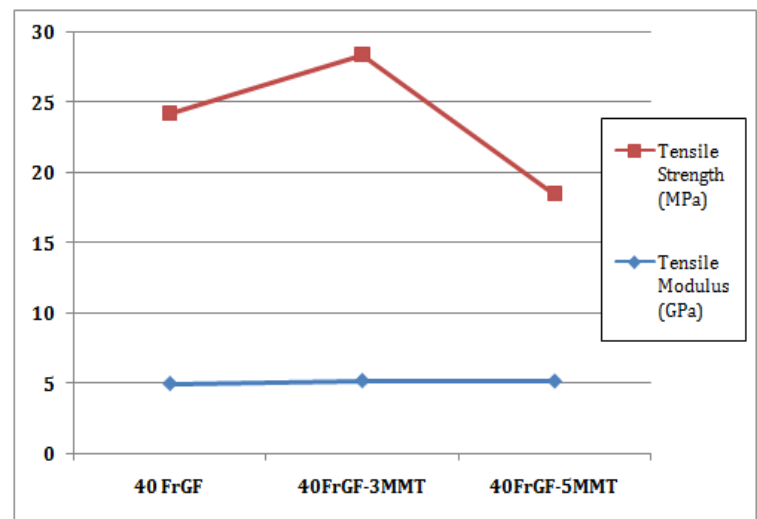

Fig. 4: Tensile properties of 40 fine rGF composites

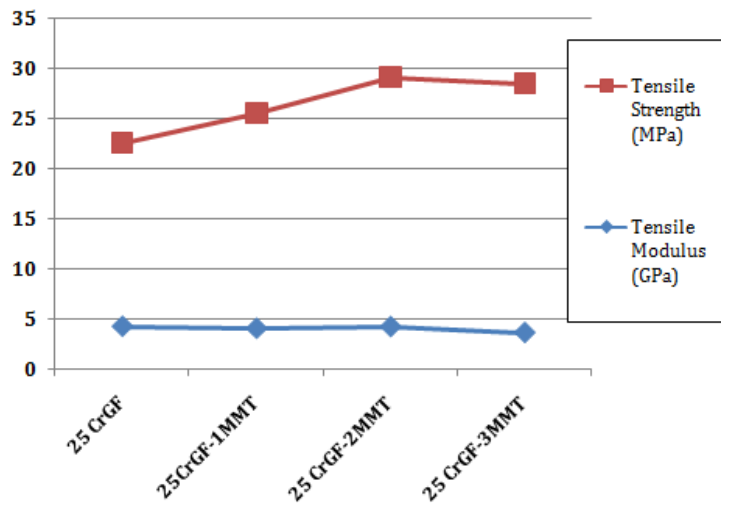

Fig. 5: Tensile properties of 25 coarse rGF composites

Fig. 6 shows the tensile stress versus tensile strain curves of hybrid $\mathrm{rGF} / \mathrm{MMT}$ composites compared to other rGF formulations. The inclusion of MMT had increased the tensile strength of the UP resin by $13.4 \%$, while the tensile modulus remains unchanged. The graph shows that fibre loading of rGF plays a major role in contributing the stiffness of the composites (Johnson, 1979). The addition of MMT in hybrid composites had increased the tensile strength and Young's Modulus respectively.

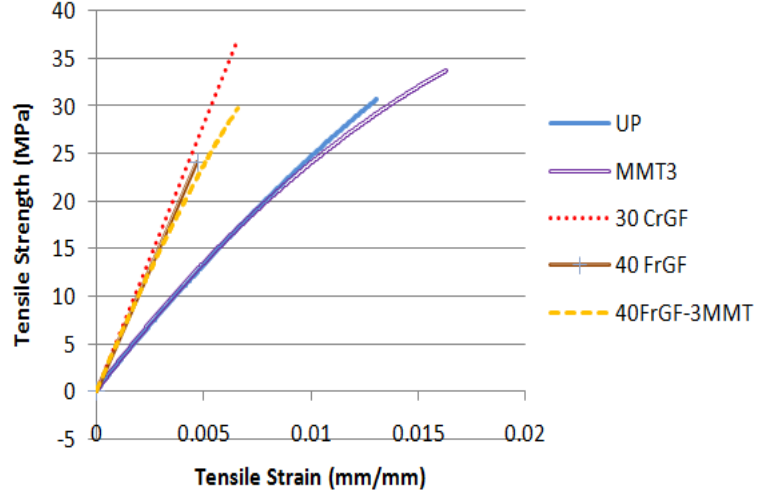

Fig. 6: Tensile stress versus tensile strain of hybrid rGF/MMT composites

As depicted in Fig. 7, existing resin can be observed on the recyclate's morphology either on the surface of a single fibre or embodied together with fibre bundles. According to Palmer (2009), glass fibre recyclates produced by mechanical recycling technique contains about 60 wt.\% resin and filler. While, glass fibre makes up $40 \mathrm{wt} \%$ of the recyclates.

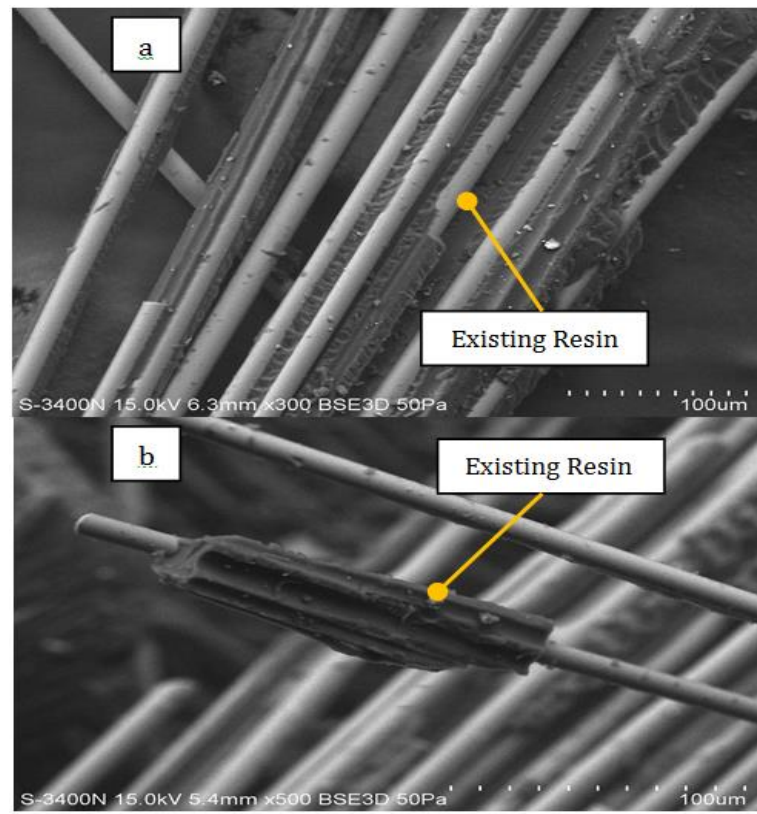

Fig. 7: Micrography of recyclates fibres. (a) fibre bundle and (b) single fibre (x300 magnification)

Recyclate particles or fragments in Fig. 8 show a much higher content of resin waste. These fragments measures between $5 \mathrm{~mm}$ to $15 \mathrm{~mm}$ were presents in coarse rGFs because the inability of fragments to pass through the siever mesh. Despite the occurrences of recyclates fragments, coarse rGF composites (30 $\mathrm{CrGF}$ ) have better tensile properties compared to any fine rGF composites (25 FrGF, 30 FrGF and 40 FrGF).

The microstructure of the tensile failure area of rGF composites can be observed in Fig. 9. The remaining resin content from GFRP waste can be noticed on the recyclate. The existing residual resin weakens the mechanical strength of the composites by hindering the tensile load to be transferred effectively onto the fibres. Fig. 9 also shows uneven 
fibre size and fibre distribution in raw rGF composites.

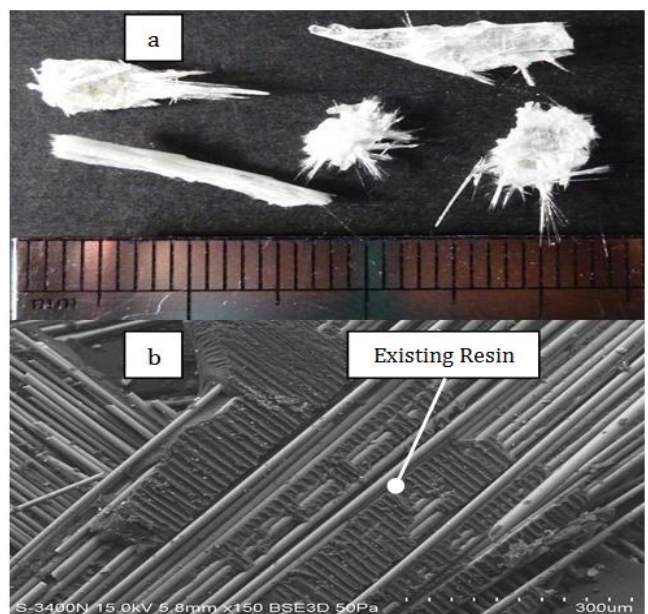

Fig. 8: (a) Image of recyclates particles, (b) SEM of recyclates particles (x150 magnification)

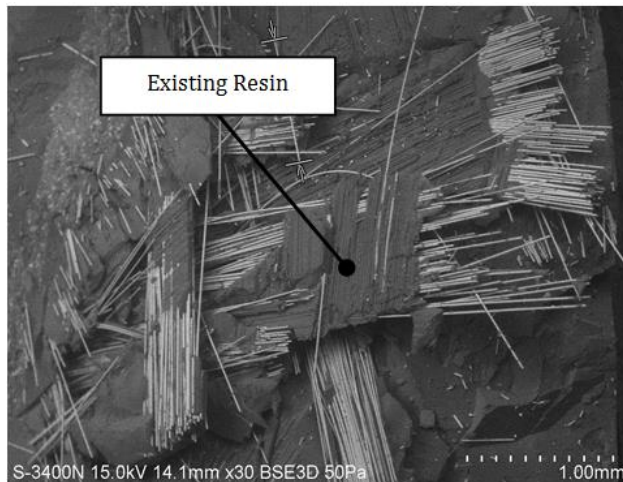

Fig. 9: SEM of fractured area of raw $25 \mathrm{rGF}$ composites

Cross section of raw rGF specimen in Fig. 10 proves that the content of raw rGF composites consists of huge amounts of powder recyclates (fibre length $<1 \mathrm{~mm}$ ). The small aspect ratio of powders does not improve the tensile strength of the composites (Figs. 11 and 12).

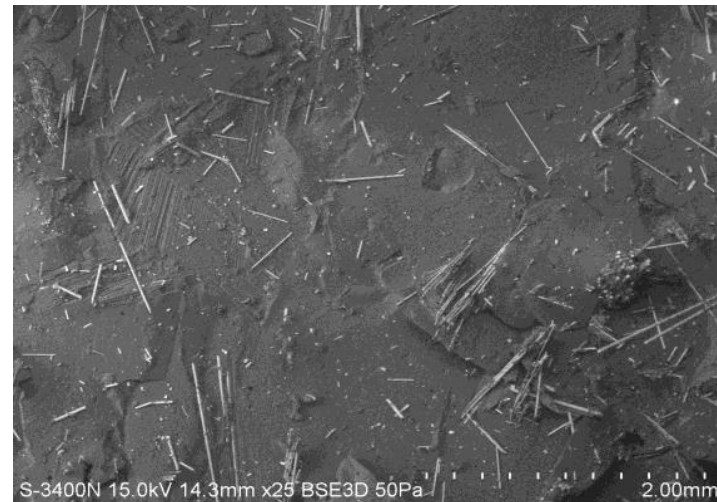

Fig. 10: SEM of fractured area of raw rGF composites

Fig. 11 and 12 show the cross section of 40rGF$3 \mathrm{MMT}$ and 40rGF-5MMT. The resin shows good adhesion towards the recyclates in 40rGF-3MMT composites. While in 40rGF-5MMT, the resin becomes degraded and less adhesive to the recyclates. This explains the low tensile strength of 40rGF-5MMT due to the lack of load transfer capability between the resin matrix and fibres interface.

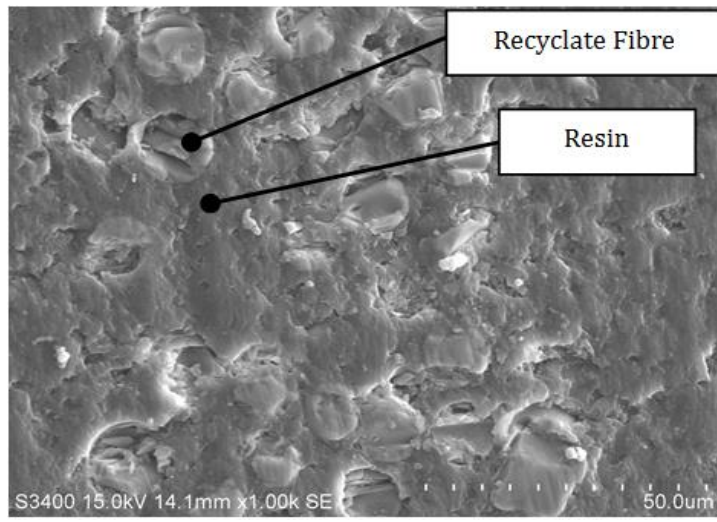

Fig. 11: SEM cross section of 40rGF-3MMT

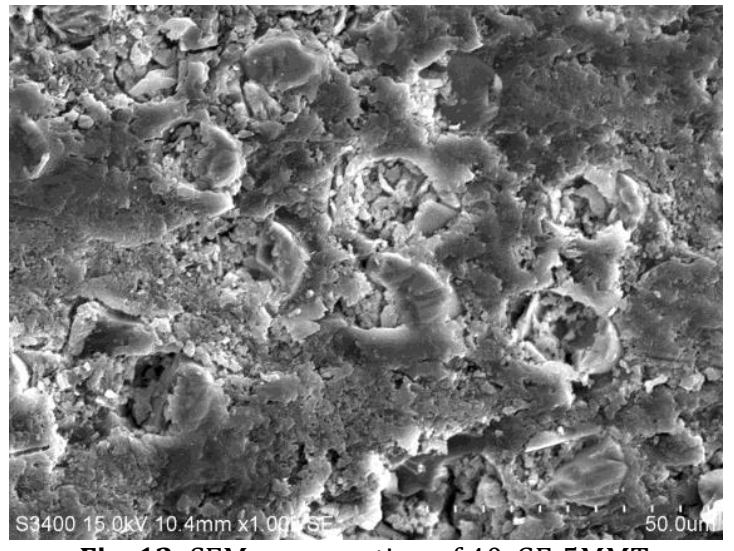

Fig. 12: SEM cross section of 40rGF-5MMT

\section{Conclusion}

In conclusion, the increased of rGF fibre loading will increased the Young's modulus or stiffness of the composites. Compared to raw rGF, sieved rGF has better tensile strength due to better fibre distribution of $\mathrm{rGF}$ and uniformed fibre length. Among the sieved rGF, coarse rGF composites which contain relatively larger aspect ratio have better tensile properties than fine rGF. However, the optimum fibre loading for coarse $\mathrm{rGF}$ is $30 \mathrm{wt} \%$ and at $40 \mathrm{wt} \%$ the tensile strength of the composites drops significantly. The inclusion of $3 \%$ MMT nanofiller in polyester resin enhances the tensile strength of $40 \mathrm{FrGF} / 3 \mathrm{MMT}$ hybrid composites by $14 \%$ than the non-hybrid 40FrGF. However, the addition of $5 \%$ MMT in $40 \mathrm{FrGF} / 5 \mathrm{MMT}$ resulted in poor tensile strength due to poor adhesion of matrix to the recyclates. From this study, it is concluded that for good tensile performance for glass fibre recyclate-polyester composites the optimal weight percentage of MMT nanoclay is between $2 \%$ to $3 \%$ for coarse $\mathrm{rGF}$ at 25 wt.\%. However, due to the viscous of UP/MMT resin and compactness of rGF in the composites, 30CrGF composites does not improved when added with MMT. As for suggestion for future study, half percent of MMT could possibly improves $30 \mathrm{CrGF}$ as it is less viscous compared to 1$3 \mathrm{wt} \%$ of MMT used in this study. 


\section{Acknowledgment}

The authors would like to thank Universiti Teknologi Malaysia for funding this research and UTM Research Management Centre (RMC) for managing the research activities under Vot. $10 \mathrm{H} 22$ and also Short Term Research Grant from Universiti Kuala Lumpur, Malaysian Institute of Industrial Technology. The authors also wish to acknowledge the contribution of Atostech Fibreglass Sdn. Bhd. in the recycling process of GFRP.

\section{References}

Asmatulu E, Twomey J, and Overcash M (2014). Recycling of fiberreinforced composites and direct structural composite recycling concept. Journal of Composite Materials, 48(5): $593-$ 608.

Bernasconi A, Rossin D, and Armanni C (2007). Analysis of the effect of mechanical recycling upon tensile strength of a short glass fibre reinforced polyamide 6,6. Engineering Fracture Mechanics, 74(4): 627-641.

Goodship V (2009). Management, recycling and reuse of waste composites. Woodhead Publishing Limited, Cambridge, UK.

Johnson AF (1979). Engineering design properties of GRP. No. 215/2 6-79 Monograph, Transport Research Laboratory, Berkshire, UK.

Kao CC, Ghita OR, Hallam KR, Heard PJ, and Evans KE (2012). Mechanical studies of single glass fibres recycled from hydrolysis process using sub-critical water. Composites Part A: Applied Science and Manufacturing, 43(3): 398-406.

Karippal JJ, Murthy HN, Rai KS, Sreejith M, and Krishna M (2011). Study of mechanical properties of epoxy/glass/nanoclay hybrid composites. Journal of Composite Materials, 45(18): 1893-1899.

Kaynak C, Nakas GI, and Isitman NA (2009). Mechanical properties, flammability and char morphology of epoxy resin/montmorillonite nanocomposites. Applied Clay Science, 46(3): 319-324.

Kornmann X, Berglund LA, Sterte J, and Giannelis EP (1998). Nanocomposites based on montmorillonite and unsaturated polyester. Polymer Engineering and Science, 38(8): 13511358.

Kusmono K and Mohd IZA (2013). Effect of clay addition on mechanical properties of unsaturated polyester/glass fiber composites. International Journal of Polymer Science, 2013: Article ID 797109, 7 pages. https://doi.org/10.1155/2013/ 797109.

Morote-Martinez V, Torregrosa-Coque R, and Martin-Martinez JM (2011). Addition of unmodified nanoclay to improve the performance of unsaturated polyester resin coating on natural stone. International Journal of Adhesion and Adhesives, 31(3): 154-163.

Otheguy ME, Gibson AG, Findon E, Cripps RM, Mendoza AO, and Castro MA (2009). Recycling of end-of-life thermoplastic composite boats. Plastics, Rubber and Composites, 38(9-10): 406-411.

Ozkoc G, Bayram G, and Tiesnitsch J (2008). Microcompounding of organoclay-ABS/PA6 blend-based nanocomposites. Polymer Composites, 29(4): 345-356.

Palmer JAT (2009). Mechanical recycling of automotive composites for use as reinforcement in thermoset composites. Ph.D. Dissertation, University of Exeter, Exeter, UK.

Parvinzadeh M, Moradian S, Rashidi A, and Yazdanshenas ME (2010). Surface characterization of polyethylene terephthalate/silica nanocomposites. Applied Surface Science, 256(9): 2792-2802.

Shokrieh MM, Kefayati AR, and Chitsazzadeh M (2012) Fabrication and mechanical properties of clay/epoxy nanocomposite and its polymer concrete. Materials and Design, 40: 443-452.

Yang Y, Boom R, Irion B, van Heerden DJ, Kuiper P, and de Wit H (2012). Recycling of composite materials. Chemical Engineering and Processing: Process Intensification, 51: 5368. 